\title{
Molecular characterization of influenza A viruses circulating in Cuba between April 2009 and August 2010
}

\author{
Amely Arencibia García, Alexander Piñon Ramos, Mayra Muné Jiménez, Belsy Acosta Herrera, Odalys \\ Valdés Ramirez, Clara Savón Valdés, Susel Oropesa Fernandez, Grehete Gonzalez Muñoz, Yudira Soto \\ Brito, Elias Guilarte García, Guelsys Gonzalez Baez, Bárbara Hernández, Angel Goyenechea \\ Fernández
}

\begin{abstract}
Department of Virology, Institute of Tropical Medicine Pedro Kouri, National Reference Laboratory of Influenza virus, Havana, Cuba
\end{abstract}

Key words: Influenza; Molecular characterization; Cuba.

J Infect Dev Ctries 2014; 8(7):929-932. doi:10.3855/jidc.4387

(Received 05 November 2013 - Accepted 11 March 2014)

Copyright (C) 2014 Arencibia et al. This is an open-access article distributed under the Creative Commons Attribution License, which permits unrestricted use, distribution, and reproduction in any medium, provided the original work is properly cited.

Influenza A viruses are one of the most important pathogens for humans. Two main subtypes of these viruses, $\mathrm{A}(\mathrm{H} 3 \mathrm{~N} 2)$ and $\mathrm{A}(\mathrm{H} 1 \mathrm{~N} 1)$, are currently circulating among human populations [1]. However, the highest mortality rates typically occur in seasons when the circulation of the influenza $\mathrm{A}(\mathrm{H} 3 \mathrm{~N} 2)$ viruses predominate over the influenza $\mathrm{A}(\mathrm{H} 1 \mathrm{~N} 1)$ and the influenza B viruses [2].

On the 11th of June 2009, the World Health Organization established phase 6 and confirmed that an influenza pandemic was taking place. This pandemic was caused by a novel A(H1N1)pdm09 influenza strain that emerged in Mexico in April 2009, and then spread worldwide through human to human transmission. The $\mathrm{A}(\mathrm{H} 1 \mathrm{~N} 1) \mathrm{pdm} 09$ influenza strain was first detected in Cuba in May 2009, and later spread throughout the country [3].

When the efficient transmission of the A (H1N1)pdm09 influenza virus from swine to humans occurred in 2009, the worldwide predominant subtype was influenza $\mathrm{A}(\mathrm{H} 3 \mathrm{~N} 2)$. The two consequences of the aforementioned interspecies transmission included: 1) the co-circulation of A(H1N1)pdm09 and A(H3N2)influenza subtypes from April 2009 to August 2010; and 2) the displacement from circulation of the $\mathrm{A}(\mathrm{H} 1 \mathrm{~N} 1)$ seasonal subtype by the A(H1N1)pdm09 subtype [4].

Mutations that affect any of the eight gene segments of influenza A viruses, especially the HA segment (and its HA1 region), may induce immune evasion by reshaping antigenic epitopes. Since molecular markers of human host adaptation were not found for the $\mathrm{A}(\mathrm{H} 1 \mathrm{~N} 1) \mathrm{pdm} 09$ viruses, unrecognized molecular determinants might have been associated with transmission to humans [5]. The evolution of circulating viruses is monitored via systematic molecular surveillance, which allows for detecting emerging genetic variants and their genetic match with the vaccine strain.

Given these points, the aim of the present study was the molecular and phylogenetic analysis of influenza A viruses circulating in Cuba between April 2009 and August 2010.

Between April 2009 and August 2010, nasopharyngeal swabs, broncheoalveolar fluids and lung tissue samples were sent from the all over the country to the National Influenza Center (NIC), located at the Influenza Virus Laboratory, Pedro Kourí Institute of Tropical Medicine (IPK), for diagnosis and surveillance purposes. All clinical samples were accompanied by a standard questionnaire containing epidemiological and clinical data, based on ethics considerations and with informed consent previously signed by each patient. Samples included in the present study were randomly selected from the total of specimens received at the NIC and they were representative for all periods (beginning, middle and the end of the epidemic season). Twenty-three clinical samples positive to influenza A viruses, four to the influenza $A(H 1 N 1)$, eight to the influenza $A(H 3 N 2)$, 
and eleven to the influenza $\mathrm{A}(\mathrm{H} 1 \mathrm{~N} 1)$ pdm09, were included in this study. For each sample, the nucleotide sequence was obtained and compared to those from the vaccine strains recommended by the WHO for the 2009-2010 Northern Hemisphere influenza season [6], such as A/Perth/16/2009 (H3N2), A/Brisbane/59/2007 (H1N1), and A/California/07/2009 (H1N1)pdm09.

Total viral RNA was extracted from clinical samples using the QIAamp Viral RNA Mini Kit (Qiagen, Valencia, USA). Amplification reactions were performed according to a previously published protocol [7]. Amplicons were sequenced using the BigDye Genome Lab Dye Terminator Cycle Sequencing Kit (Beckman Coulter, Brea, USA). MEGA v.5.05 by means of the Kimura two-parameter model was used to calculate genetic distances. Phylogenetic trees were obtained with MrBayes v.3.1.2 software [8], and were visualized with Dendroscope v.2.7.4. Potential N-glycosylation sites for the influenza $\mathrm{A}(\mathrm{H} 1 \mathrm{~N} 1) \mathrm{pdm} 09$ were predicted through NetNGlyc server 1.0.

The sequences reported in this study can be located in the GenBank database under the following accession numbers: JX853783; JX853785; JX853786JX853787; $\quad$ KC914966-KC914967; KC934965;JQ922291; JQ922292; JQ922294JQ922297; JQ922273; JQ922275; JQ922277; JQ922286; JQ922286; JQ922288; and KC914933KC914936.

All the HA sequences corresponding to the $\mathrm{A}(\mathrm{H} 3 \mathrm{~N} 2)$ subtype were closely related to the A/Perth/16/2009 lineage (Figure 1a), with similarities of $97.84 \%$ and $98.21 \%$ for nucleotide and amino acid sequences, respectively. In particular, amino acid sequences were characterized by the presence of substitutions S241I and T212A in antigenic site D, and $\mathrm{K} 144 \mathrm{~N}$ in the antigenic site A. Nevertheless, Falchi et al.[9] reported amino acid variations for the antigenic sites $\mathrm{A}, \mathrm{B}, \mathrm{D}$ and $\mathrm{E}$ of the influenza $\mathrm{A}(\mathrm{H} 3 \mathrm{~N} 2)$ viruses. Additionally, Dapat et al.[10] detected five mutations in the HA gene (domain HA1) affecting the antigenic sites B, C, D and E. Suwannakarn et al. reported similar findings [11]. For the $\mathrm{A}(\mathrm{H} 3 \mathrm{~N} 2)$ influenza viruses, amino acid substitutions clustered generally in the antigenic sites A, B, D and E.

The sequences corresponding to the $\mathrm{A}(\mathrm{H} 1 \mathrm{~N} 1)$ subtype were closely associated with the A/Brisbane/59/2007lineage (Figure 1b). The homology with the A/Brisbane/59/2007 lineage was $97.22 \%$ and $98.45 \%$ for nucleotide and amino acid sequences, respectively.
Figure1. Phylogenetic relationships of HA1 sequence of the influenza A viruses circulating between 2009 and 2010. A) influenza A(H3N2); B) seasonal influenza $\mathrm{A}(\mathrm{H} 1 \mathrm{~N} 1)$; and C) influenza $\mathrm{A}(\mathrm{H} 1 \mathrm{~N} 1)$ pdm09.

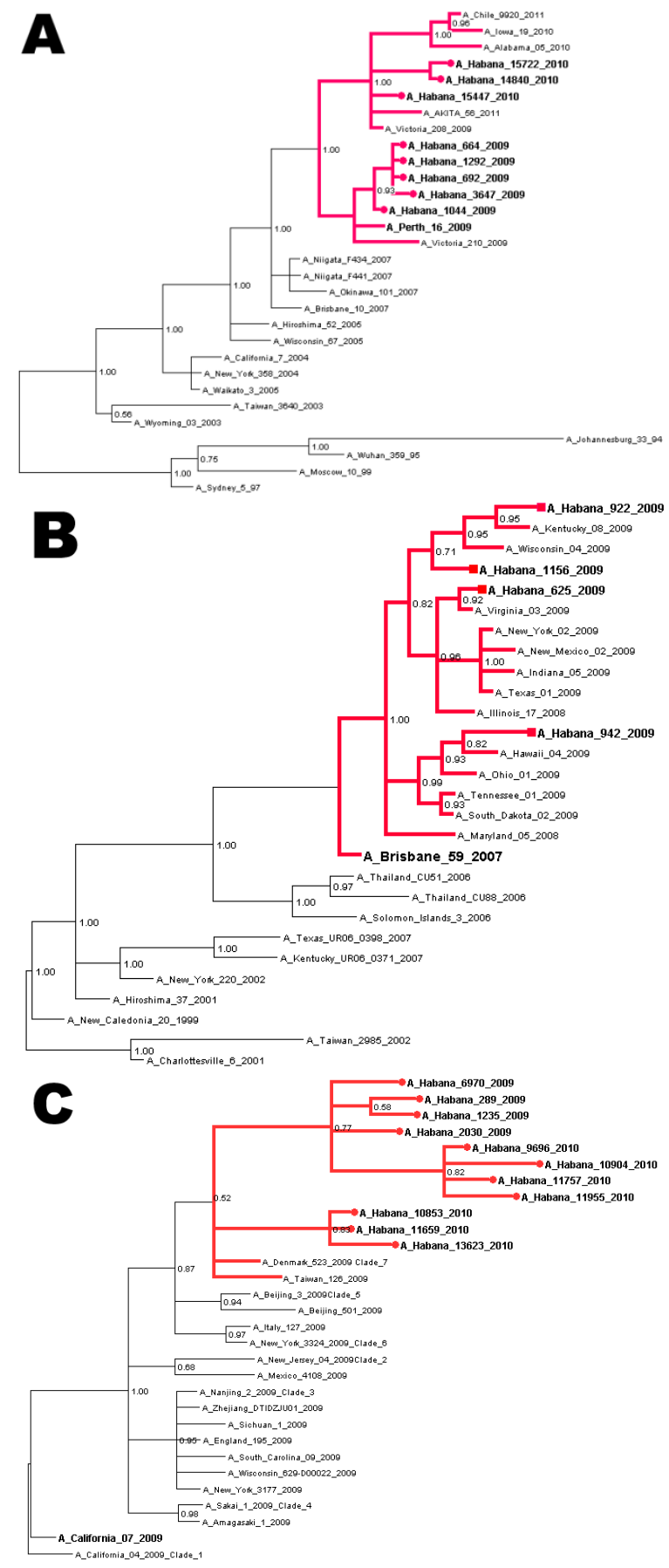

Cuban sequences (in bold) obtained between April 2009 and August 2010 The phylogenetic trees were constructed using MrBayes v.3.1.2 software, and incorporating the GTR $+\mathrm{G}$ model of nucleotide substitution. Generation number and sampling frequency were set to 1000000 and 1000, respectively. Every clade was supported by Bayesian posterior probabilities (BPP). 
Substitutions $\mathrm{S} 145 \mathrm{~N}$ in the antigenic site $\mathrm{Ca}$, and A193T, G189S and G189A in the antigenic site Sb, were detected. Suwannakarn et al.[11] found amino acid variations for the $\mathrm{A}(\mathrm{H} 1 \mathrm{~N} 1)$ influenza viruses in the antigenic sites $\mathrm{Sb}, \mathrm{Ca}$ and $\mathrm{Cb}$. These findings indicate that the amino acid substitutions affecting the antigenic regions of the HA were more frequent for influenza $\mathrm{A}(\mathrm{H} 3 \mathrm{~N} 2)$ than for seasonal influenza $\mathrm{A}(\mathrm{H} 1 \mathrm{~N} 1)$ viruses. Interestingly, the difference in mutation rates may be explained by the evolutionary dynamics of these viruses. For the immunization with an influenza vaccine to be effective, frequent replacements of the $\mathrm{A}(\mathrm{H} 3 \mathrm{~N} 2)$ vaccine strain are required, as the $\mathrm{A}(\mathrm{H} 3 \mathrm{~N} 2)$ subtype exhibits a higher rate of antigenic variations when compared with the $\mathrm{A}$ (H1N1) subtype [11].

Cuban sequences corresponding to the A(H1N1)pdm09 subtype were closely related to the A/California/07/2009 lineage (Figure 1c), with similarities of $97.25 \%$ and $98.21 \%$ for nucleotide and amino acid sequences, respectively. In addition to mutations found for the $\mathrm{A}(\mathrm{H} 1 \mathrm{~N} 1)$ subtype, mutations N441I and V272I were detected. Substitution D222E was also identified in one sequence. With an unknown biological function, D222E is a low-frequency mutation that has been detected in other countries. Mutation D222G, detected also in other countries and associated with disease severity, was not detected for the $\mathrm{A}(\mathrm{H} 1 \mathrm{~N} 1) \mathrm{pdm} 09$ influenza viruses in Cuba. This finding may explain the low mortality rate observed in Cuba. Furthermore, the phylogenetic analysis indicated that all Cuban sequences belonged to the clade 7 (posterior probability $>0.90$ ). This clade, which is characterized by S203T mutation, was responsible for most of the pandemic burden worldwide [12]. Whether the predominance of S203T mutation in the antigenic site $\mathrm{Ca}$ stems from immune selection, adaptation to human hosts, or fitness optimization remains to be determined [13]. The S162N mutation in the antigenic site Sa, represented the acquisition of a N-glycosylation site.

In agreement with other studies, we confirm the genetic variability of the A (H3N2), (H1N1) and (H1N1)pdm09 influenza viruses. Moreover, our findings emphasize the significance of systematic molecular surveillance for the effective management of influenza epidemics and pandemics. The genetic characterization of influenza strains circulating in Cuba has contributed not only to complete the molecular variability profiles for influenza viruses in Latin American and the Caribbean region, but also to support the WHO Global Influenza Surveillance
Program. Our phylogenetic analyses, which can be compared with other phylogenetic analysis worldwide, constitute a starting point for future research on the genetic variability of influenza viruses.

\section{References}

1. Lin YP, Gregory V, Bennett M, Hay A (2004) Recent changes among human influenza viruses. Virus Res 103: 4752 .

2. Simonsen L, Clarke MJ, Williamson GD, Stroup DF, Arden NH, Schonberger LB (1997) The impact of influenza epidemics on mortality: introducing a severity index. Am J Public Health 87: 1944-1950.

3. Acosta B, Pinon A, Valdes O, Savon C, Arencibia A, Guilarte E, Grehete G, Oropesa S, Guelsys G, Hernandez B Goyenechea A, Muné M, Kouri V, Guzmán MG, Llop A (2012) Rapid diagnosis of pandemic (H1N1) 2009 in Cuba. Emerg Infect Dis 18: 336-337.

4. Blyth CC, Kelso A, McPhie KA, Ratnamohan VM, Catton M, Druce JD, Smith DW, Williams SH, Huang QS, Lopez L, Schoub BD, Venter M, Dwyer DE. (2010) The impact of the pandemic influenza A(H1N1) 2009 virus on seasonal influenza A viruses in the southern hemisphere, 2009. Euro Surveill 15.

5. Medina A, García-Sastre A (2011). Influenza A viruses: new research developments. Nature 9: 590-603

6. Barr I, McCauley J, Cox N, Daniels R, Engelhardt O, Fukuda K, Grohmann G, Hay A, Kelso A, Klimov A Takato Odagiri, Derek Smith, Colin Russell, Masato Tashiro, Richard Webby, John Wood, Zhiping Ye, Wenqing Zhang (2010) Epidemiological, antigenic and genetic characteristics of seasonal influenza $\mathrm{A}(\mathrm{H} 1 \mathrm{~N} 1), \mathrm{A}(\mathrm{H} 3 \mathrm{~N} 2)$ and $\mathrm{B}$ influenza viruses: basis for the WHO recommendation on the composition of influenza vaccines for use in the 2009-2010 Northern Hemisphere season. Vaccine 28: 1156-1167.

7. Ruiz-Carrascoso G, Casas I, Pozo F, Perez-Gonzalez C, Reina J, Perez-Brena P (2010) Development and implementation of influenza a virus subtyping and detection of genotypic resistance to neuraminidase inhibitors. J Med Virol 82: 843853.

8. Ronquist F, Huelsenbeck JP (2003) MrBayes 3: Bayesian phylogenetic inference under mixed models. Bioinformatics. Bioinformatics 19: 1572-1574.

9. Falchi A, Amoros JP, Arena C, Arrighi J, Casabianca F, Andreoletti L, Turbelin C, Flahault A, Blanchon T, Hanslik T, Laurent Varesi (2011) Genetic Structure of Human A/H1N1 and A/H3N2 Influenza Virus on Corsica Island: Phylogenetic Analysis and Vaccine Strain Match, 2006-2010. PLoS One 6: e24471.

10. Dapat C, Suzuki Y, Kon M, Tamura T, Saito R, Dapat IC, Yamazaki O, Odagiri T, Fujisaki S, Suzuki H (2011) Phylogenetic Analysis of an Off-Seasonal Influenza Virus A (H3N2) in Niigata, Japan, 2010. Jpn J Infect Dis 64: 237-241.

11. Suwannakarn K, Chieochansin T, Thongmee C, Makkoch J, Praianantathavorn K, Theamboonlers A, Sreevatsan S, Poovorawan Y (2010) Molecular evolution of human H1N1 and H3N2 influenza A virus in Thailand, 2006-2009. PLoS One 5: e9717. 
12. Mullick J, Cherian SS, Potdar VA, Chadha MS, Mishra AC (2011) Evolutionary dynamics of the influenza A pandemic (H1N1) 2009 virus with emphasis on Indian isolates: Evidence for adaptive evolution in the HA gene. Infect Genet Evol 11: 997-1005.

13. Anton A, Pozo F, Niubo J, Casas I, Pumarola T (2012) Influenza $\mathrm{A}(\mathrm{H} 1 \mathrm{~N} 1) \mathrm{pdm} 09$ virus: viral characteristics and genetic evolution. Enferm Infecc Microbiol Clin 30 Suppl 4:10-17.

\section{Corresponding author}

Amely Arencibia García

Department of Virology,

Institute of Tropical Medicine Pedro Kouri, National Reference

Laboratory of Influenza virus, Havana, Cuba, CP. 11400

Phone: + 5372553549

Fax: + 5372046051

Email: amely@ipk.sld.cu

Conflict of interests: No conflict of interests is declared. 